\title{
Toward a Common Understanding of Diet-Exercise Strategies to Manipulate Fuel Availability for Training and Competition Preparation in Endurance Sport
}

\author{
Louise M. Burke \\ Australian Institute of Sport and Australian Catholic University \\ John A. Hawley \\ Australian Catholic University \\ Asker Jeukendrup \\ Loughborough University \\ James P. Morton \\ Liverpool John Moores University \\ Trent Stellingwerff \\ Canadian Sport Institute Pacific and University of Victoria British Columbia \\ Ronald J. Maughan \\ University of St Andrews
}

\begin{abstract}
From the breakthrough studies of dietary carbohydrate and exercise capacity in the 1960s through to the more recent studies of cellular signaling and the adaptive response to exercise in muscle, it has become apparent that manipulations of dietary fat and carbohydrate within training phases, or in the immediate preparation for competition, can profoundly alter the availability and utilization of these major fuels and, subsequently, the performance of endurance sport (events $>30$ min up to $24 \mathrm{hr}$ ). A variety of terms have emerged to describe new or nuanced versions of such exercise-diet strategies (e.g., train low, train high, lowcarbohydrate high-fat diet, periodized carbohydrate diet). However, the nonuniform meanings of these terms have caused confusion and miscommunication, both in the popular press and among the scientific community. Sports scientists will continue to hold different views on optimal protocols of fuel support for training and competition in different endurance events. However, to promote collaboration and shared discussions, a commonly accepted and consistent terminology will help to strengthen hypotheses and experimental/experiential data around various strategies. We propose a series of definitions and explanations as a starting point for a more unified dialogue around acute and chronic manipulations of fat and carbohydrate in the athlete's diet, noting philosophies of approaches rather than a single/definitive macronutrient prescription. We also summarize some of the key questions that need to be tackled to help produce greater insight into this exciting area of sports nutrition research and practice.
\end{abstract}

Keywords: carbohydrate periodization, LCHF diet, train high, train low

\footnotetext{
Burke is with Australian Institute of Sport, Belconnen, Australia. Burke and Hawley are with the Mary MacKillop Institute for Health Research, Australian Catholic University, Melbourne, Australia. Jeukendrup is with the School of Sport, Exercise and Health Sciences, Loughborough University, Loughborough, United Kingdom. Morton is with the Research Institute for Sport and Exercise Sciences, Liverpool John Moores University, Liverpool, United Kingdom. Stellingwerff is with Canadian Sport Institute Pacific, Victoria, British Columbia, Canada; and the Department of Exercise Science, Physical \& Health Education, University of Victoria British Columbia, Victoria, British Columbia, Canada. Maughan is with the School of Medicine, University of St Andrews, St Andrews, United Kingdom. Address author correspondence to Louise M. Burke at Louise.burke@ausport.gov.au.
}

Fifty years ago, Scandinavian scientists used the needle biopsy technique to sample skeletal muscle, including their own, allowing them to identify mechanisms by which manipulation of the carbohydrate $(\mathrm{CHO})$ content of the preceding diet could alter exercise endurance (Hultman, 1967). This work built on earlier studies (Krogh \& Lindhard, 1920; Christensen \& Hansen, 1939) of the effects of the macronutrient composition of the diet on fuel utilization and exercise capacity; however, these earlier investigators were limited by the techniques available at the time and by the contemporary understanding of the regulation of muscle metabolism. Research undertaken during the 1960s and 1970s on glycogen "supercompensation" spanned mechanistic descriptions of the 
cellular events underpinning the improvements in exercise capacity (Ahlborg et al., 1967; Bergstrom et al., 1967; Hermansen et al., 1967) to real-world proof that dietary CHO interventions in laboratory settings could translate into enhanced sports performance (Karlsson \& Saltin, 1971).

The outcomes of these activities included a publication in Nature (Bergstrom \& Hultman, 1966) and the rapid adoption of new dietary practices by the athletic community. For example, as early as May 1968, Dr. Griffith Pugh and the International Athletes' Club organized two $40-\mathrm{km}$ races for 10 top-class race walkers; half of the group prepared with a high-CHO diet for the first race, whereas the other half did so for the second. Their findings - that the walkers achieved significantly faster times over the final $10 \mathrm{~km}$ of their high-CHO trial-were passed on to the British competitors at the Mexico Olympic Games (Hyman, 1970). Furthermore, British runner Ron Hill attributed at least part of his success at the 1969 European Marathon Championships to a version of the $\mathrm{CHO}$ supercompensation diet described by Hermansen et al. (1967). The final outcome of this work was the introduction of the term "carbohydrate loading" into the general lexicon, with such popularity that it would become almost synonymous with sports nutrition. It is unlikely that any modern sports nutrition intervention will ever achieve the trifecta of a publication in the highest impact scientific journal, rapid adoption by its target audience to achieve success in elite sport, and household fame. Since then, many scientists have continued to refine aspects of this work to evolve modern sports nutrition into a vibrant environment of applied research leading to practice. There is no doubt that the interaction of diet and exercise provides a powerful tool for the study of the regulation of muscle metabolism and to enhance metabolic health and sports performance.

One of the downsides of the proliferation of activities across many stakeholders, including researchers, clinicians, coaches, and athletes, is that a variety of terms have emerged to describe new or nuanced versions of exercise-nutrition strategies that target similar areas of interest. The nonuniform use of terms has subsequently caused confusion and miscommunication in both the popular press and the scientific community. Even within the toolbox of such strategies, there is confusion over the names of the tools, how they should be used, and what they might achieve in reengineering the muscle. This arises because of the different nomenclature used in the original studies and the tweaking of both names and protocols in further research or real-world applications. In some cases, the same term may mean different things in the same literature but also have another meaning in an adjoining field for coaches/athletes. For example, the term "train low" has been used to describe a single acute training session in which the availability of muscle $\mathrm{CHO}$ and/ or exogenous $\mathrm{CHO}$ has been manipulated to "lower" levels before and/or during the session by a variety of techniques that have different metabolic and cellular consequences (for reviews, see Bartlett et al., 2015; Hawley et al., 2018; Impey et al., 2018). However, the term has also been used to describe a chronic training period in which such strategies were undertaken in differing combinations over many days to weeks (Hansen et al., 2005; Yeo et al., 2008); furthermore, to many sports scientists and coaches, "train low" is more likely to be aligned with altitude/hypoxia exposure protocols (Girard et al., 2013).

Historically, the scientific literature has provided confusing information and nonmeaningful terminology, such as using the ratio of energy contributed by $\mathrm{CHO}$ in the athlete's diet as the single metric of the adequacy of CHO intake (Burke et al., 2004). However, even this literature presents erroneous information. For example, proponents of low-CHO high-fat dietary philosophies commonly state that contemporary sports nutrition guidelines promote high $\mathrm{CHO}$ intakes at all times for all athletes (Brukner, 2013; Noakes et al., 2014; Volek et al., 2015). Yet, as far back as 2003, official recommendations from an International Olympic Committee expert panel noted that fuel demands differed between different types of events or training intensities and volumes, leading to a sliding scale of daily $\mathrm{CHO}$ intake targets and the promotion of specific scenarios, rather than a universal recommendation for aggressive CHO fueling strategies (Burke et al., 2004). Indeed, between and among even elite endurance athletes, training loads can vary from 10 to $12 \mathrm{hr} /$ week, with the duration of a key session being 60-120 min (e.g., track runner), up to 25-30 hr/week, with single sessions lasting for 4-6 hr (e.g., triathletes, cyclists). Accordingly, a further update in 2010 recommended that $\mathrm{CHO}$ availability, rather than absolute intake, be used to evaluate the athlete's dietary CHO consumption (Burke et al., 2011). Here, the amount and timing of daily $\mathrm{CHO}$ intake are defined in relation to the fuel cost of the day's exercise load-recently termed "fuel for the work required" (Impey et al., 2018). Accordingly, "high CHO availability" denotes that this intake is able to provide sufficient endogenous and/or exogenous CHO supplies to meet the demands of the muscle (and central nervous system), whereas "low $\mathrm{CHO}$ availability" signifies a shortfall between supplies and exercise/ energy demand (Burke et al., 2011). Indeed, according to the example of variability in workloads between and within even elite athletes previously provided, any given amount of $\mathrm{CHO}$ and its timing of intake might achieve "high $\mathrm{CHO}$ availability" for one athlete or one day's training, whereas in another context it would be considered "low."

The 2010 update refined the concept of the different and changing $\mathrm{CHO}$ requirements between and within athletes by explicitly stating that: (a) high $\mathrm{CHO}$ availability is required only for sessions in which training or competition involves higher intensity workloads and the need to perform optimally or train with high-quality outputs and/or maximize recovery; (b) training loads, which are light and/or based on low-moderate intensity exercise, may not need to be supported by high $\mathrm{CHO}$ availability; and (c) there is an emerging interest in the concept of deliberately exercising with low $\mathrm{CHO}$ availability in some training sessions to take advantage of upregulated cellular signaling and adaptive responses to the increased metabolic training stress (Burke et al., 2011). The most recent sports nutrition guidelines (Thomas et al., 2016) have strengthened their recognition of this last point, noting increased confidence in the molecular underpinning of training with low CHO availability (Hawley et al., 2018; Hearris et al., 2018; Impey et al., 2018), published case studies of its use by elite athletes (Stellingwerff, 2012), and research evidence, at least in subelite athletes, that its careful integration into a training program can lead to superior performance (Marquet et al., 2016a, 2016b). Indeed, the latest guidelines include acknowledgment of potential benefits from a personalized approach to manipulating CHO availability within the training diet (Thomas et al., 2016; Jeukendrup 2017a).

The press and social media amplify the confusion by mispresenting/misreporting sports nutrition research or practice and by generally oversimplifying the sophistication of contemporary sports nutrition knowledge (Burke, 2017). In July 2016, a Twitter war erupted after Tour De France winner Chris Froome uploaded a photo of his breakfast on a rest day during the middle of this grueling stage race. This single picture of eggs, smoked salmon, and avocado caused an avalanche of claims and counterclaims 


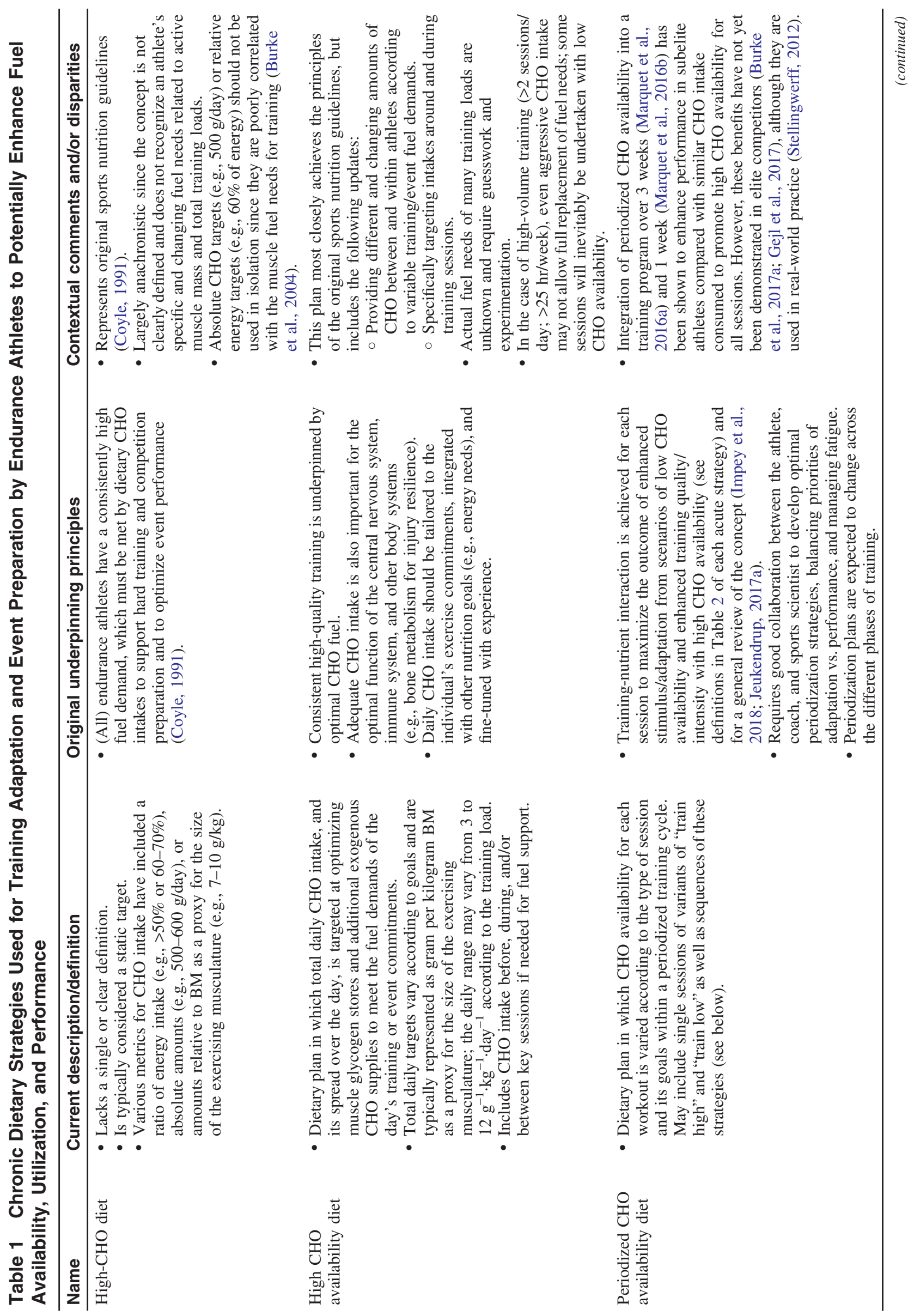




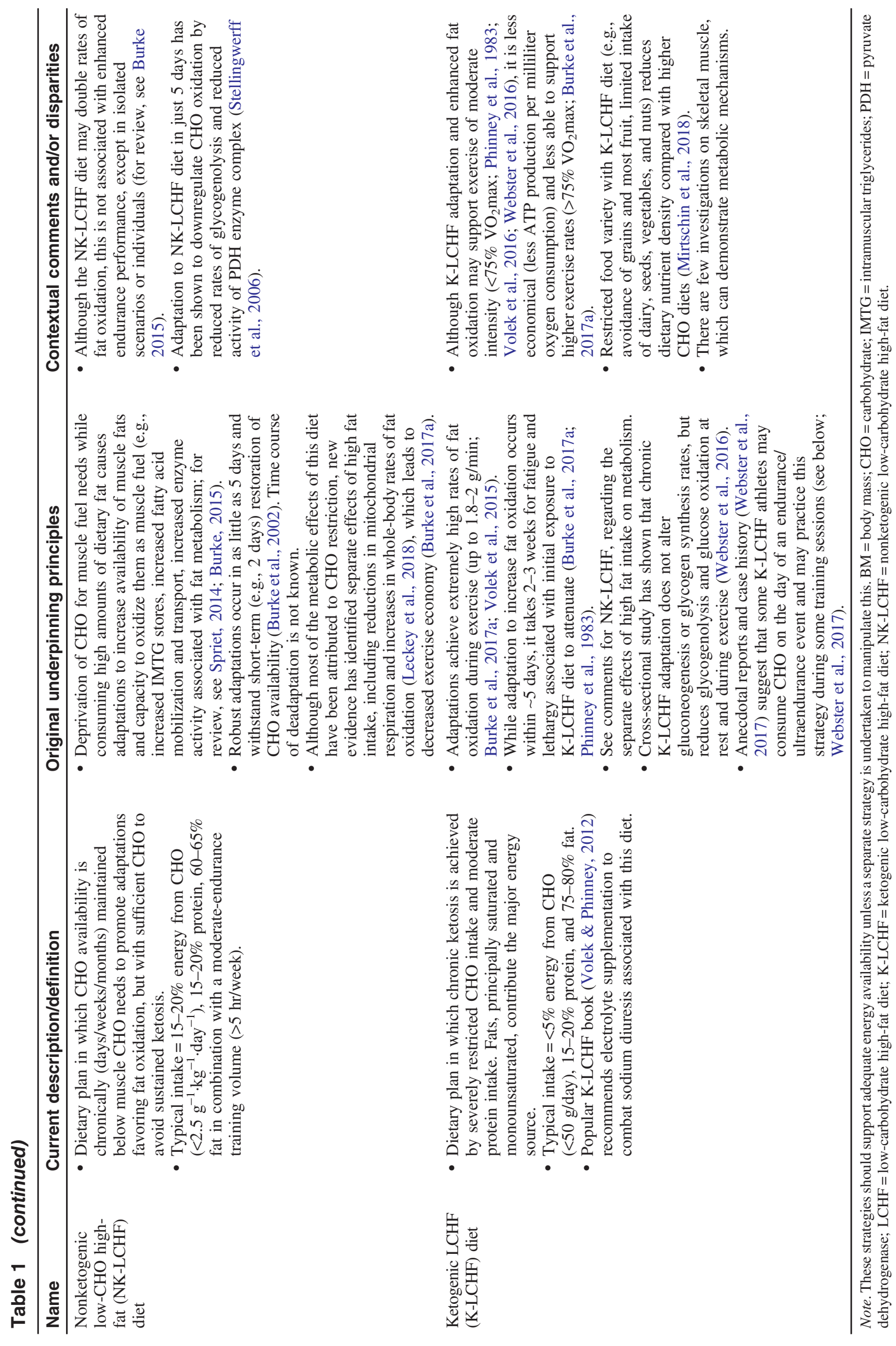




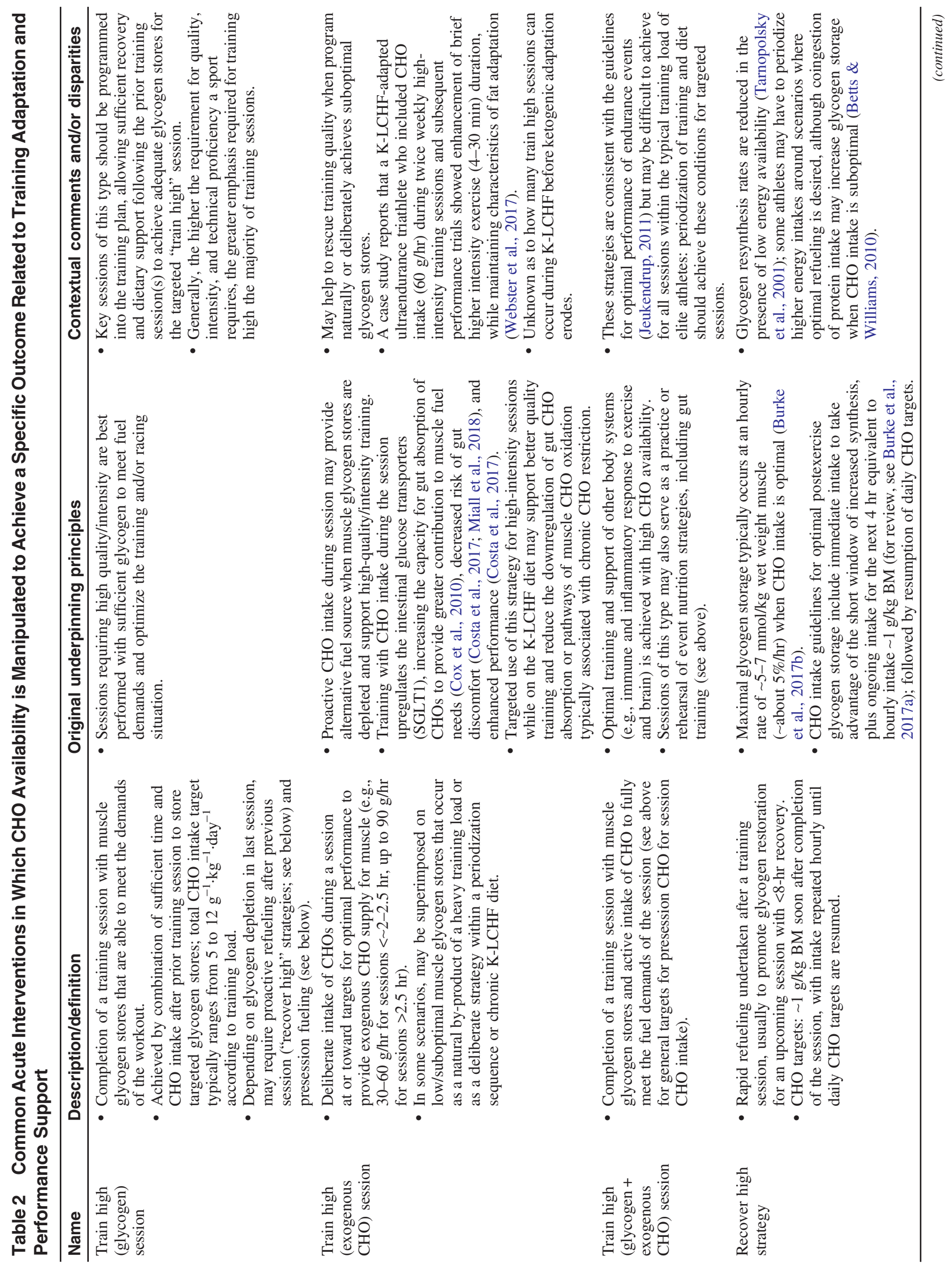




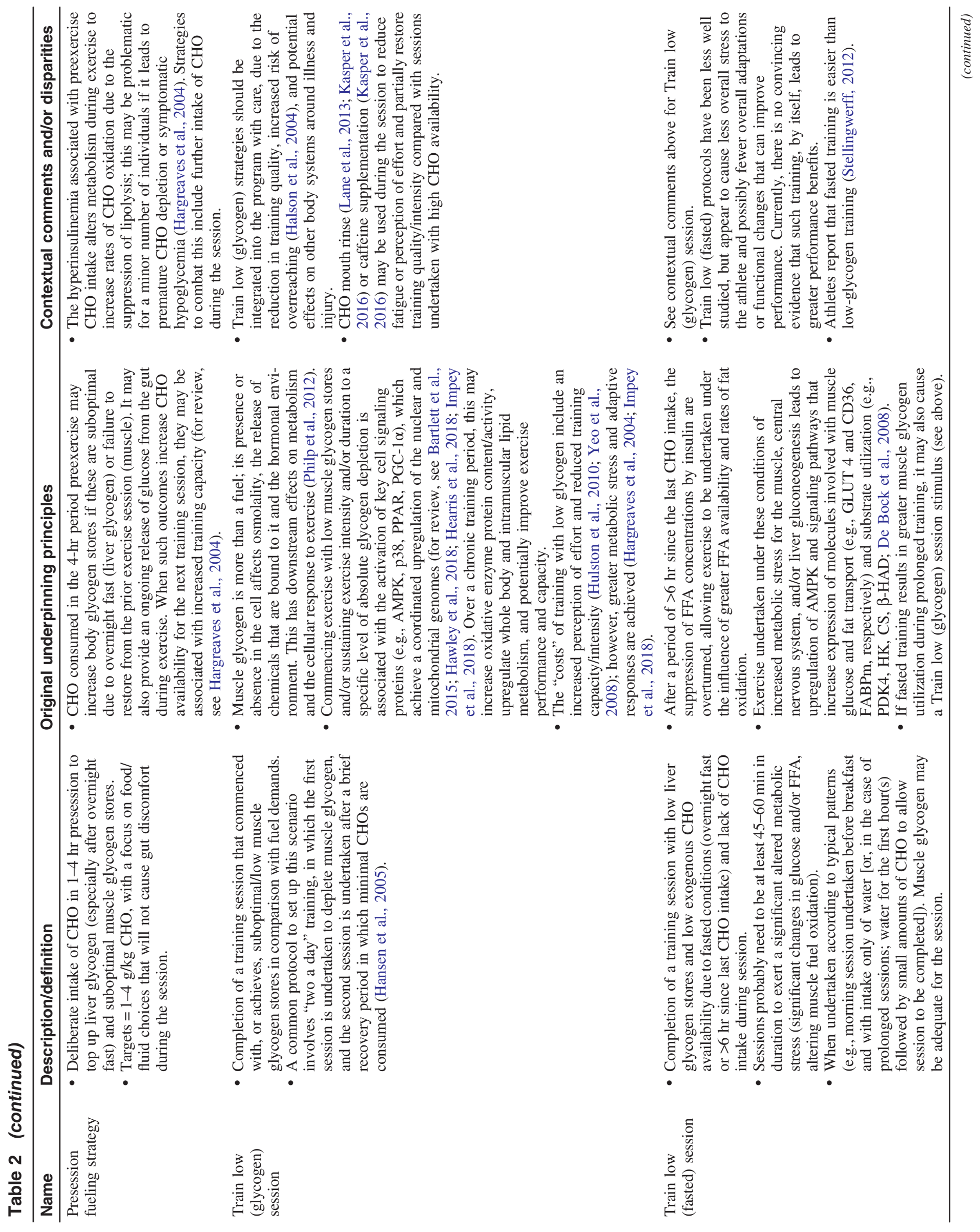




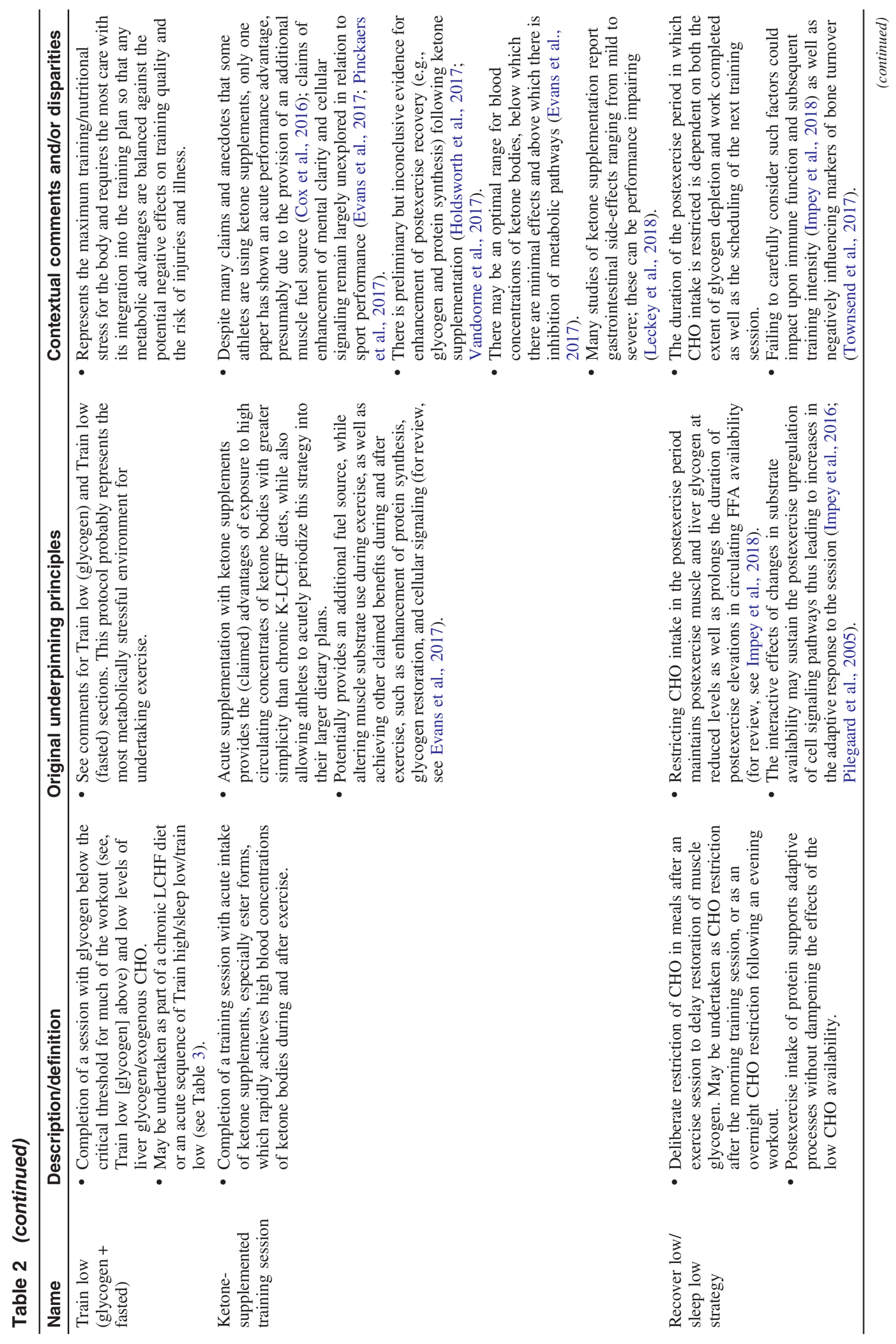




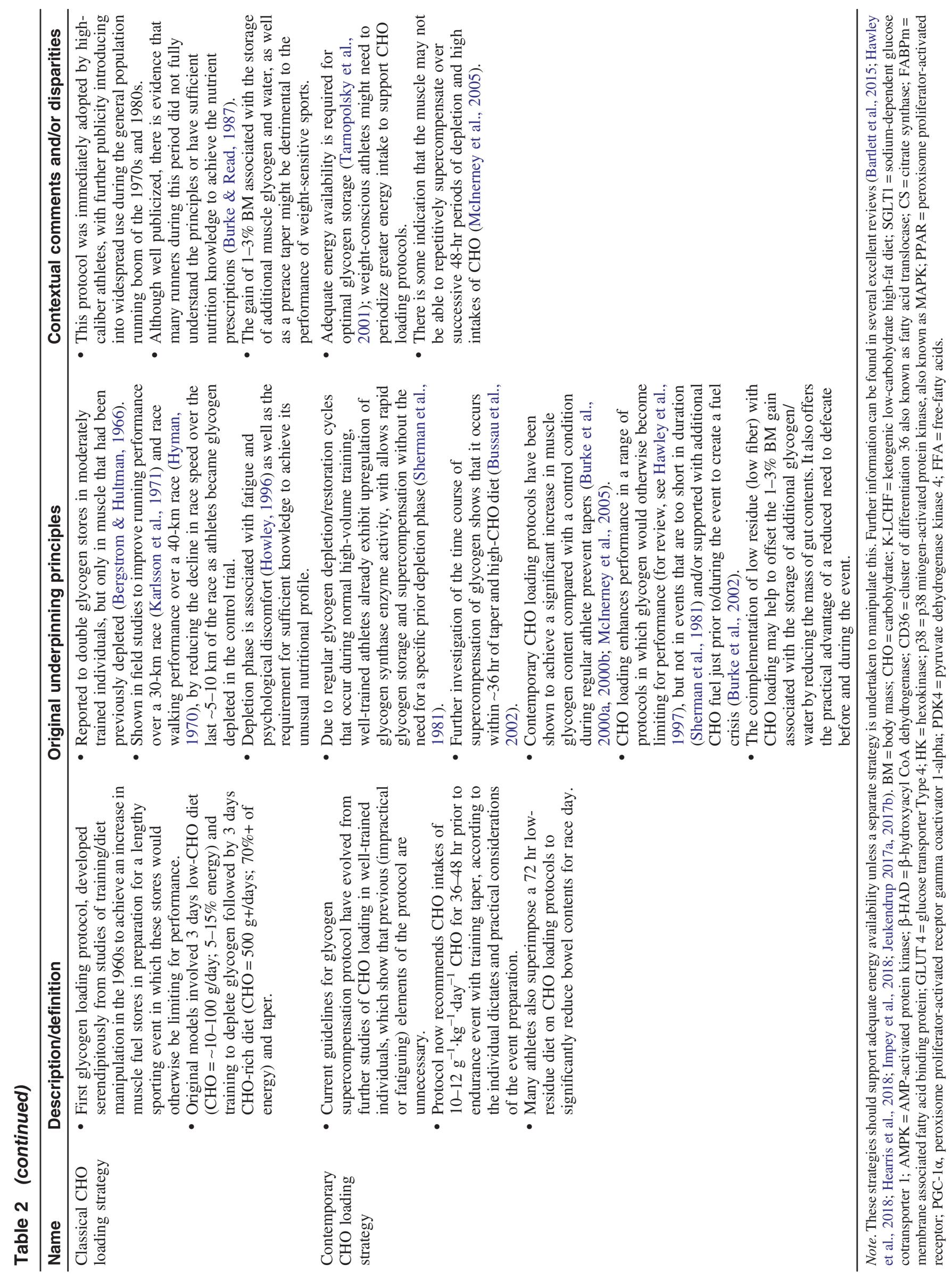




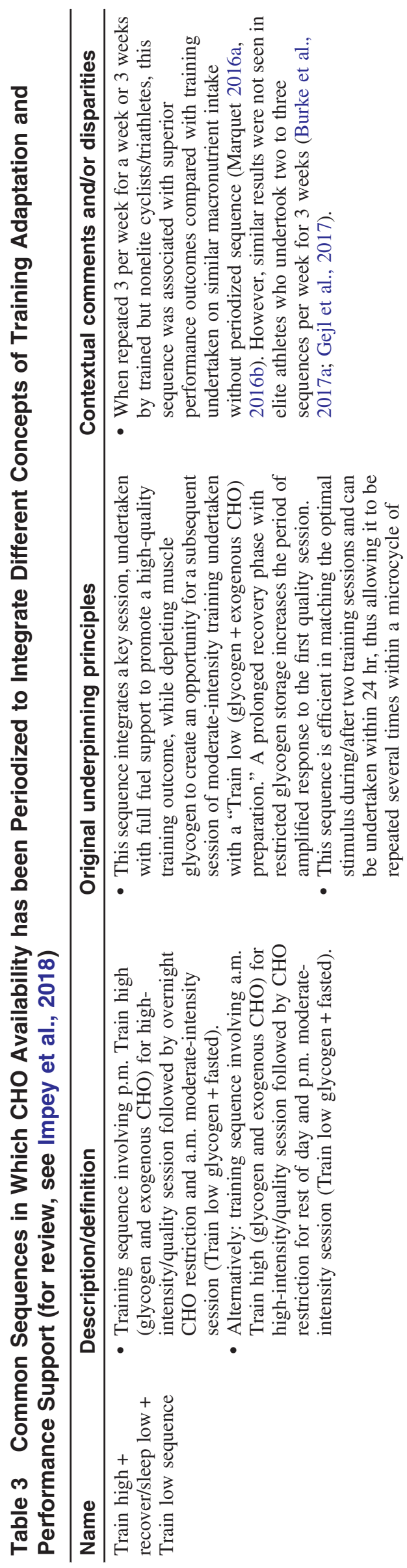

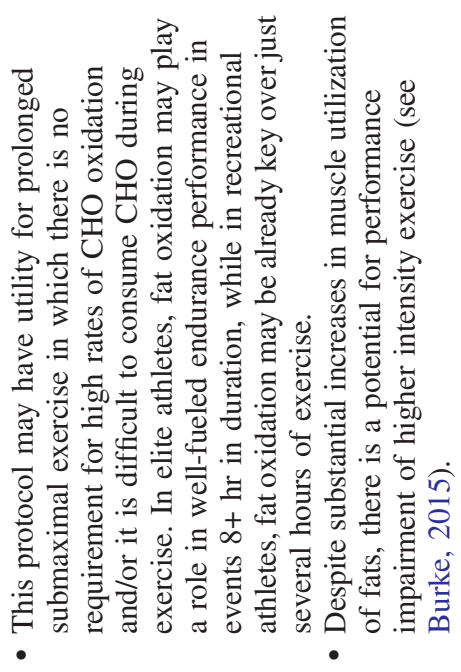

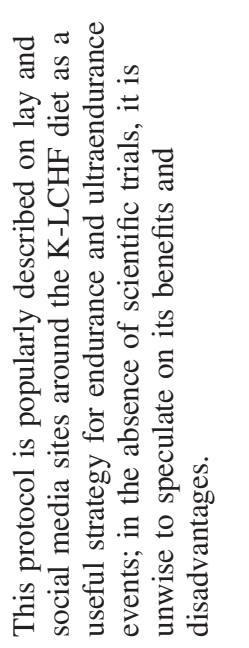

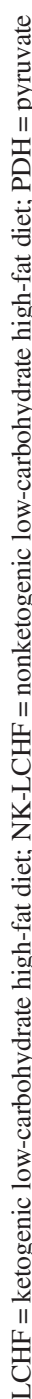

จ

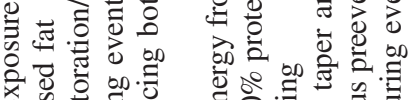

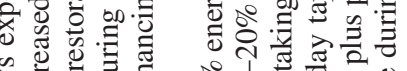

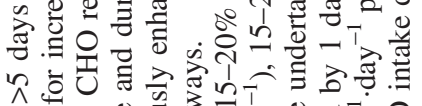

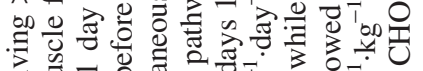

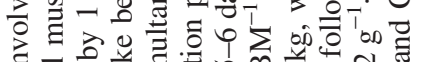

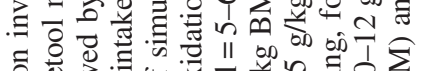

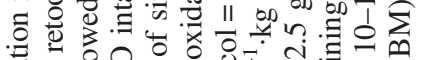

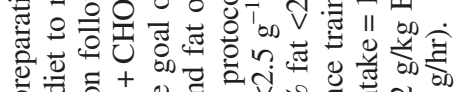

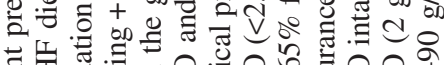

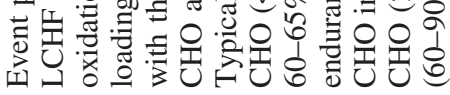
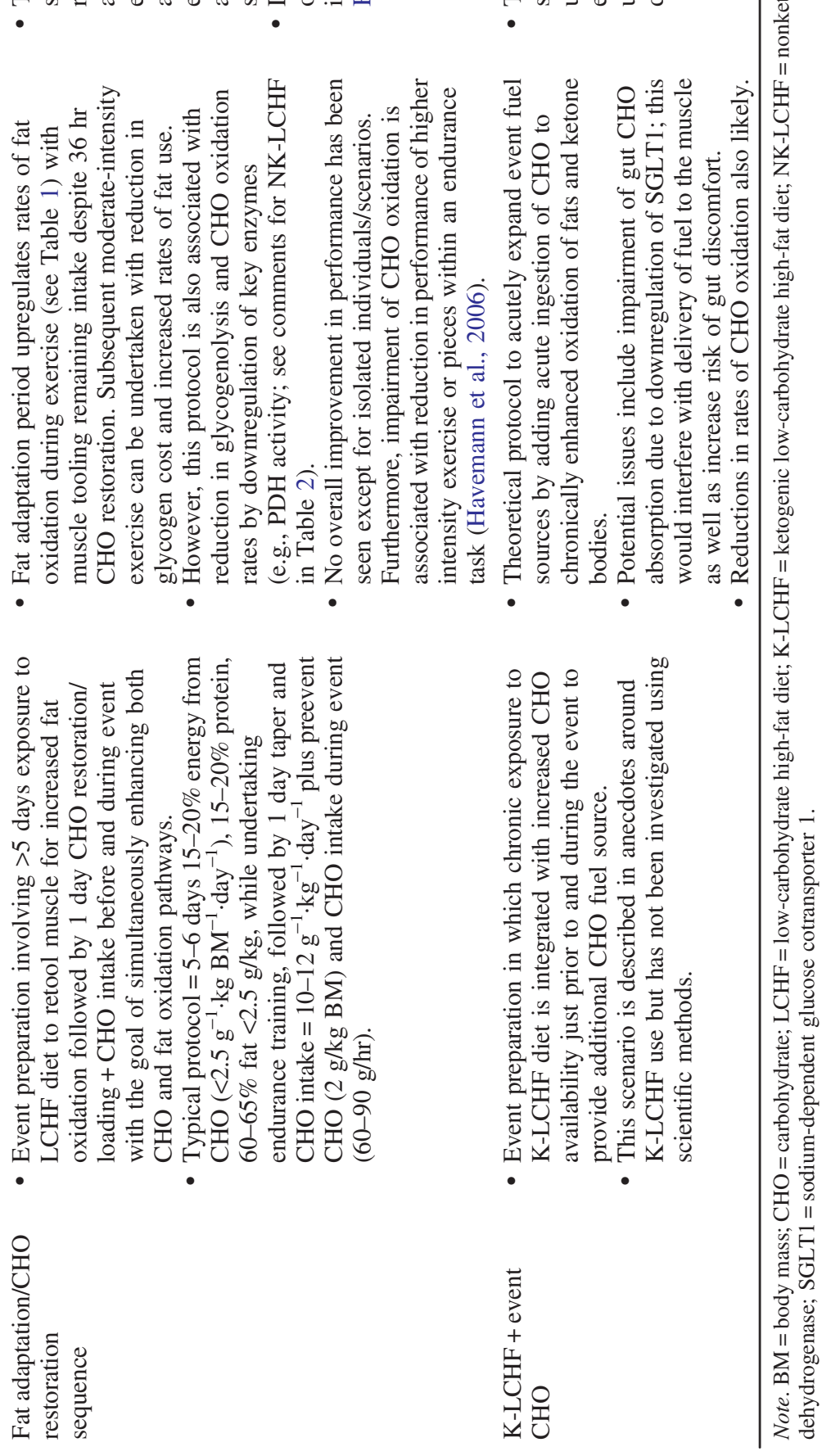
about Froome's advocacy of the low-CHO high-fat diet, despite wider evidence presented by the athlete himself that he follows a plan in which $\mathrm{CHO}$ availability is periodized according to his specific goals (Palfreeman, 2016). Further support and background are available from an author of this commentary who works with this athlete and has written extensively on the general philosophy of "fueling for the work required" (Hearris et al., 2018; Impey et al., 2018), as well as nutrition support for the Tour de France in

\section{Table 4 Targeted Questions for Future Research}

High-priority questions to be answered around periodization of $\mathrm{CHO}$ availability in the training diet and for event preparation

- What are the fuel costs, glycogen utilization rates, and associated $\mathrm{CHO}$ intake requirements of various training sessions commonly undertaken by athletes? (for review, see Areta \& Hopkins, 2018)

- Are there dietary factors that can enhance muscle glycogen storage either in situations where $\mathrm{CHO} /$ energy intake meets guidelines for optimal intake or in situations where these are inadequate?

- What is the threshold of "low muscle glycogen" availability needed preexercise or during exercise to amplify the signaling response to exercise or to be maintained postexercise to maintain the increase in postexercise signaling? (Impey et al., 2018)

- Are there differences between elite athletes and their subelite counterparts in terms of metabolic and performance responses to deliberate strategies to periodize $\mathrm{CHO}$ availability in the training diet?

- What is the optimal type, ratio, and integration of "train low" CHO strategies versus "train high" strategies within a periodized training diet to optimize the overall outcomes of a training block?

- What is the optimal type, ratio, and integration of "train high" $\mathrm{CHO}$ fueling practice to optimize $\mathrm{CHO}$ oxidation and gastrointestinal function prior to racing in endurance athletes?

- What are the immediate and functional consequences of acute or chronic exposure to low $\mathrm{CHO}$ availability during exercise on cytokines (e.g., interleukin-6) and downstream responses of other body systems such as hepcidin/iron status (Badenhorst et al., 2015), osteocalcin/CTX-1/bone status (Sale et al., 2015), and immune status (Hennigar et al., 2017)?

- What is the optimal protocol for periodic acute exposure to high exogenous $\mathrm{CHO}$ availability during a training session to overcome some of the negative systemic effects of low glycogen availability (e.g., to promote better quality training, reverse effects on the brain, immune system, gut absorption and other organs/body systems), while retaining the (claimed) benefits of chronic K-LCHF diet?

- What is the time course of the reversal of impairment of muscle CHO oxidation associated with adaptation to NK-LCHF or K-LCHF interventions and can this be achieved, while retaining some of the adaptations to increase capacity for fat oxidation?

- What is the relative exercise intensity beyond which there is an impairment of performance if $\mathrm{CHO}$ oxidation rates are impaired?

- What are the long-term effects of the differences of lower micronutrient density and fiber content of a K-LCHF diet on health?

- Do long-term adaptations to a K-LCHF diet enhance metabolism and performance, and what is the time course of these adaptations?

- Are there any long-term metabolic, health, or performance effects of exposure to high circulating levels of ketone bodies and can these be replicated by the use of ketone supplements?

- Is there an optimal range of blood ketone body concentrations that should be targeted by acute or chronic strategies to achieve ketosis?

Note. $\mathrm{CTX}-1=\mathrm{COOH}$-terminal telopeptide region of collagen Type 1; $\mathrm{CHO}=$ carbohydrate; $\mathrm{K}-\mathrm{LCHF}=$ ketogenic low-carbohydrate high-fat diet; NK-LCHF $=$ nonketogenic low-carbohydrate high-fat diet. particular (Morton \& Fell, 2016). Nevertheless, a Google search can quickly locate a range of lay pieces that claim that Froome's success is due to low-CHO high-fat. Ironically, Team Sky recently released data to illustrate the sophisticated periodization of body mass and energy/CHO intakes according to the demands of each stage in a cycling tour, including estimates of Froome's intake on the critical 19th day of his 2018 Giro D'Italia title: an astonishing 6,663 kcal (27.98 MJ) and $18.9 \mathrm{~g} / \mathrm{kg} \mathrm{CHO} \mathrm{(Fordyce,} \mathrm{2018).}$

It is likely, and indeed healthy, that scientists will continue to hold different views on a variety of sports nutrition themes, including different ways in which fuel support for training and competition preparation can be organized to promote performance according to the specific demands of the event. However, we propose that both research scientists and practitioners require collaboration and shared discussions, underpinned by a commonly accepted and consistent terminology, which serve to strengthen hypotheses and experimental/experiential data around various strategies. We also propose that athletes and coaches would be better served by less confusion and misinformation in all levels of literature. Therefore, we propose the following table of definitions and explanations as a starting point for a more unified dialogue (Tables 1-3), and we encourage our colleagues in this area of research and practice to provide as much objective detail as possible about the dietary strategies with which they experiment and apply in the field with athletes. Indeed, this issue contains a methods paper with a lengthy explanation of the principles, practices, and outcomes of organizing a tightly controlled diettraining intervention of this type (Mirtschin et al., 2018). We note that our efforts typically describe the philosophy of different approaches rather than a single/definitive macronutrient prescription. This is necessitated by the need for great clarity around optimal protocols for various strategies, but more so because the variability of the training loads/modes undertaken by athletes is too great to allow a single "one size fits all" approach to nutrition support. Accordingly, we hope our efforts will be appreciated, adopted, and further evolved toward greater definition consistency and precision and detail around optimal fueling strategies. Table 4 summarizes some of the key questions that still need to be tackled to help produce this insight.

\section{Acknowledgment}

All authors contributed to the preparation of this commentary. No conflicts of interest are declared.

\section{References}

Ahlborg, B., Bergstrom, J., Brohult, J., Ekelund, L.G., Hultman, E., \& Maschio, G. (1967). Human muscle glycogen content and capacity for prolonged exercise after different diets. Forsvarsmedicin, 3, 85-99.

Areta, J.L., \& Hopkins, W.G. (2018). Skeletal muscle glycogen content at rest and during endurance exercise in humans: A meta-analysis. Sports Medicine. Advance online publication. doi:10.1007/s40279018-0941-1

Badenhorst, C.E., Dawson, B., Cox, G.R., Laarakkers, C.M., Swinkels, D.W., \& Peeling, P. (2015). Acute dietary carbohydrate manipulation and the subsequent inflammatory and hepcidin responses to exercise. European Journal of Applied Physiology, 115(12), 2521-2530. PubMed ID: 26335627 doi:10.1007/s00421-015-3252-3

Bartlett, J.D., Hawley, J.A., \& Morton, J.P. (2015). Carbohydrate availability and exercise training adaptation: Too much of a good thing? 
European Journal of Sport Science, 15(1), 3-12. doi:10.1080/ 17461391.2014.920926

Bergstrom, J., Hermansen, L., Hultman, E., \& Saltin, B. (1967). Diet, muscle glycogen and physical performance. Acta Physiologica Scandinavica, 71, 140-150. PubMed ID: 5584523 doi:10.1111/j.17481716.1967.tb03720.x

Bergstrom, J., \& Hultman, E. (1966). Muscle glycogen synthesis after exercise: An enhancing factor localized to the muscle cells in man. Nature, 210, 309-310. PubMed ID: 5954569 doi:10.1038/210309a0

Betts, J.A., \& Williams, C. (2010). Short-term recovery from prolonged exercise exploring the potential for protein ingestion to accentuate the benefits of carbohydrate supplements. Sports Medicine, 40(11), 941-959. PubMed ID: 20942510 doi:10.2165/11536900-00000000000000

Brukner, P. (2013). Challenging beliefs in sports nutrition: Are two "core principles" proving to be myths ripe for busting? British Journal of Sports Medicine, 47(11), 663-664. doi:10.1136/bjsports-2013092440

Burke, L.M. (2015). Re-examining high-fat diets for sports performance: Did we call the "nail in the coffin" too soon? Sports Medicine, 45(Suppl. 1), 33-49. doi:10.1007/s40279-015-0393-9

Burke, L.M. (2017). Communicating sports science in the age of the Twittersphere. International Journal of Sport Nutrition and Exercise Metabolism, 27(1), 1-5. PubMed ID: 28301302 doi:10.1123/ijsnem. 2017-0057

Burke, L.M., Angus, D.J., Cox, G.R., Cummings, N.K., Febbraio, M.A., Gawthorn, K., ... Hargreaves, M. (2000a). Effect of fat adaptation and carbohydrate restoration on metabolism and performance during prolonged cycling. Journal of Applied Physiology, 89(6), 2413-2421. doi:10.1152/jappl.2000.89.6.2413

Burke, L.M., Hawley, J.A., Angus, D.J., Cox, G.R., Clark, S., Cummings, N.K., . . Hargreaves, M. (2002). Adaptations to short-term high-fat diet persist during exercise despite high carbohydrate availability. Medicine \& Science in Sports \& Exercise, 34(1), 83-91. PubMed ID: 11782652 doi:10.1097/00005768-200201000-00014

Burke, L.M., Hawley, J.A., Schabort, E.J., St Clair Gibson, A., Mujika, I., \& Noakes, T.D. (2000b). Carbohydrate loading failed to improve $100-\mathrm{km}$ cycling performance in a placebo-controlled trial. Journal of Applied Physiology, 88, 1284-1290. doi:10.1152/jappl.2000.88.4. 1284

Burke, L.M., Hawley, J.A., Wong, S.H., \& Jeukendrup, A.E. (2011). Carbohydrates for training and competition. Journal of Sports Sciences, 29(Suppl. 1), S17-S27. doi:10.1080/02640414.2011.585473

Burke, L.M., Kiens, B., \& Ivy, J.L. (2004). Carbohydrates and fat for training and recovery. Journal of Sports Sciences, 22(1), 15-30. PubMed ID: 14971430 doi:10.1080/0264041031000140527

Burke, L.M., \& Read, R.S.D. (1987). A study of carbohydrate loading techniques used by marathon runners. Canadian Journal of Sport Science, 12, 6-10.

Burke, L.M., Ross, M.L., Garvican-Lewis, L.A., Welvaert, M., Heikura, I.A., Forbes, S.G., . . . Hawley, J.A. (2017a). Low carbohydrate, high fat diet impairs exercise economy and negates the performance benefit from intensified training in elite race walkers. Journal of Physiology, 595(9), 2785-2807. doi:10.1113/JP273230

Burke, L.M., van Loon, L.J.C., \& Hawley, J.A. (2017b). Postexercise muscle glycogen resynthesis in humans. Journal of Applied Physiology, 122(5), 1055-1067. doi:10.1152/japplphysiol.00860. 2016

Bussau, V.A., Fairchild, T.J., Rao, A., Steele, P.D., \& Fournier, P.A. (2002). Carbohydrate loading in human muscle: An improved 1 day protocol. European Journal of Applied Physiology, 87, 290-295. doi:10.1007/s00421-002-0621-5
Christensen, E.H., \& Hansen, O. (1939). III. Arbeitsfähigkeit und Ernährung Skandinavisches Archiv Für. Physiologie, 81(1), 160-171.

Costa, R.J.S., Miall, A., Khoo, A., Rauch, C., Snipe, R., Camoes-Costa, V., \& Gibson, P. (2017). Gut-training: The impact of two weeks repetitive gut-challenge during exercise on gastrointestinal status, glucose availability, fuel kinetics, and running performance. Applied Physiology, Nutrition, and Metabolism, 42(5), 547-557. PubMed ID: 28177715 doi:10.1139/apnm-2016-0453

Cox, G.R., Clark, S.A., Cox, A.J., Halson, S.L., Hargreaves, M., Hawley, J.A., ... Burke, L.M. (2010). Daily training with high carbohydrate availability increases exogenous carbohydrate oxidation during endurance cycling. Journal of Applied Physiology, 109(1), 126-134. PubMed ID: 20466803 doi:10.1152/japplphysiol. 00950.2009

Cox, P.J., Kirk, T., Ashmore, T., Willerton, K., Evans, R., Smith, A., .. . Clarke, K. (2016). Nutritional ketosis alters fuel preference and thereby endurance performance in athletes. Cell Metabolism, 24(2), 256-268. PubMed ID: 27475046 doi:10.1016/j.cmet.2016.07.010

Coyle, E.F. (1991). Timing and method of increased carbohydrate intake to cope with heavy training, competition and recovery. Journal of Sports Sciences, 9(Suppl.), 29-52. doi:10.1080/02640419108729865

De Bock, K., Derave, W., Eijnde, B.O., Hesselink, M.K., Koninckx, E., Rose, A.J., ... Hespel, P. (2008). Effect of training in the fasted state on metabolic responses during exercise with carbohydrate intake. Journal of Applied Physiology, 104(4), 1045-1055. PubMed ID: 18276898 doi:10.1152/japplphysiol.01195.2007

Evans, M., Cogan, K.E., \& Egan, B. (2017). Metabolism of ketone bodies during exercise and training: Physiological basis for exogenous supplementation. Journal of Physiology, 595(9), 2857-2871. PubMed ID: 27861911 doi:10.1113/JP273185

Fordyce, T. (2018). Chris Froome: Team Sky's unprecedented release of data reveals how British rider won Giro d'Italia. Retrieved from https://www.bbc.com/sport/cycling/44694122

Gejl, K.D., Thams, L.B., Hansen, M., Rokkedal-Lausch, T., Plomgaard, P., Nybo, L., .. Ortenblad, N. (2017). No superior adaptations to carbohydrate periodization in elite endurance athletes. Medicine \& Science in Sports \& Exercise, 49(12), 2486-2497. PubMed ID: 28723843 doi:10.1249/MSS.0000000000001377

Girard, O., Amann, M., Aughey, R., Billaut, F., Bishop, D.J., Bourdon, P., ... Schumacher, Y.O. (2013). Position statement-altitude training for improving team-sport players' performance: Current knowledge and unresolved issues. British Journal of Sports Medicine, 47(Suppl. 1), i8-i16. doi:10.1136/bjsports-2013-093109

Halson, S.L., Lancaster, G.I., Achten, J., Gleeson, M., \& Jeukendrup, A.E. (2004). Effects of carbohydrate supplementation on performance and carbohydrate oxidation after intensified cycling training. Journal of Applied Physiology, 97(4), 1245-1253. PubMed ID: 15155717 doi: 10.1152/japplphysiol.01368.2003

Hansen, A.K., Fischer, C.P., Plomgaard, P., Andersen, J.L., Saltin, B., \& Pedersen, B.K. (2005). Skeletal muscle adaptation: Training twice every second day vs. training once daily. Journal of Applied Physiology, 98(1), 93-99. PubMed ID: 15361516 doi:10.1152/japplphysiol. 00163.2004

Hargreaves, M., Hawley, J.A., \& Jeukendrup, A.E. (2004). Pre-exercise carbohydrate and fat ingestion: Effects on metabolism and performance. Journal of Sports Sciences, 22(1), 31-38. PubMed ID: 14971431 doi:10.1080/0264041031000140536

Havemann, L., West, S., Goedecke, J.H., McDonald, I.A., St-Clair Gibson, A., Noakes, T.D., \& Lambert, E.V. (2006). Fat adaptation followed by carbohydrate-loading compromises high-intensity sprint performance. Journal of Applied Physiology, 100(1), 194-202. PubMed ID: 16141377 doi:10.1152/japplphysiol.00813.2005 
Hawley, J.A., Lundby, C., Cotter, J.D., \& Burke, L.M. (2018). Maximizing cellular adaptation to endurance exercise in skeletal muscle. Cell Metabolism. 27, 962-976. PubMed ID: 29719234 doi:10. 1016/j.cmet.2018.04.014

Hawley, J.A., Schabort, E.J., Noakes, T.D., \& Dennis, S.C. (1997). Carbohydrates for training and competition. Sports Medicine, 24(2), 73-81.

Hearris, M.A., Hammond, K.M., Fell, J.M., \& Morton, J.P. (2018). Regulation of muscle glycogen metabolism during exercise: Implications for endurance performance and training adaptations. Nutrients, 10(3), pii: E298. PubMed ID: 29498691 doi:10.3390/nu10030298

Hennigar, S.R., McClung, J.P., \& Pasiakos, S.M. (2017). Nutritional interventions and the IL-6 response to exercise. FASEB Journal, 31(9), 3719-3728. PubMed ID: 28507168 doi:10.1096/fj. 201700080R

Hermansen, L., Hultman, E., \& Saltin, B. (1967). Muscle glycogen during prolonged severe exercise. Acta Physiologica Scandinavica, 71, 129-139. PubMed ID: 5584522 doi:10.1111/j.1748-1716.1967. tb03719.x

Holdsworth, D.A., Cox, P.J., Kirk, T., Stradling, H., Impey, S.G., \& Clarke, K. (2017). A ketone ester drink increases postexercise muscle glycogen synthesis in humans. Medicine \& Science in Sports \& Exercise, 49(9), 1789-1795. PubMed ID: 28398950 doi:10.1249/ MSS.0000000000001292

Howley, P. (1996). In the long run-Steve Moneghetti (p. 133). Ringwood, Australia: Penguin Books Australia.

Hulston, C.J., Venables, M.C., Mann, C.H., Martin, C., Philp, A., Baar, K., \& Jeukendrup, A.E. (2010). Training with low muscle glycogen enhances fat metabolism in well-trained cyclists. Medicine \& Science in Sports \& Exercise, 42(11), 2046-2055. PubMed ID: 20351596 doi: 10.1249/MSS.0b013e3181dd5070

Hultman, E. (1967). Muscle glycogen in man determined in needle biopsy specimens: Method and normal values. Scandinavian Journal of Clinical and Laboratory Investigation, 19(3), 209-217. PubMed ID: 6057997 doi:10.3109/00365516709090628

Hyman, M. (1970). Diet and athletics. British Medicine of Journal, 4(5726), 52. doi:10.1136/bmj.4.5726.52-b

Impey, S.G., Hammond, K.M., Shepherd, S.O., Sharples, A.P., Stewart, C., Limb, M., ... Morton, J.P. (2016). Fuel for the work required: A practical approach to amalgamating train-low paradigms for endurance athletes. Physiological Reports, 4(10), pii: e12803. PubMed ID: 27225627 doi:10.14814/phy2.12803

Impey, S.G., Hearris, M.A., Hammond, K.M., Bartlett, J.D., Louis, J., Close, G.L., \& Morton, J.P. (2018). Fuel for the work required: A theoretical framework for carbohydrate periodization and the glycogen threshold hypothesis. Sports Medicine, 48(5), 1031-1048. PubMed ID: 29453741 doi:10.1007/s40279-018-0867-7

Jeukendrup, A.E. (2011). Nutrition for endurance sports: Marathon, triathlon, and road cycling. Journal of Sports Sciences, 29(Suppl. 1), S91-S99. doi:10.1080/02640414.2011.610348

Jeukendrup, A.E. (2017a). Periodized nutrition for athletes. Sports Medicine, 47(Suppl. 1), 51-63. doi:10.1007/s40279-017-0694-2

Jeukendrup, A.E. (2017b). Training the gut for athletes. Sports Medicine, 47(Suppl. 1), 101-110. doi:10.1007/s40279-017-0690-6

Karlsson, J., \& Saltin, B. (1971). Diet, muscle glycogen, and endurance performance. Journal of Applied Physiology, 31, 203-206. PubMed ID: 5558241 doi:10.1152/jappl.1971.31.2.203

Kasper, A.M., Cocking, S., Cockayne, M., Barnard, M., Tench, M., Parker, L., ... Morton, J.P. (2016). Carbohydrate mouth rinse and caffeine improves high-intensity interval running capacity when carbohydrate restricted. European Journal of Sport Science, 16(5), 560-568. doi:10.1080/17461391.2015.1041063
Krogh, A., \& Lindhard, J. (1920). The relative value of fat and carbohydrate as sources of muscular energy: With appendices on the correlation between standard metabolism and the respiratory quotient during rest and work. Biochemical Journal, 14, 290-363.

Lane, S.C., Bird, S.R., Burke, L.M., \& Hawley, J.A. (2013). Effect of a carbohydrate mouth rinse on simulated cycling time-trial performance commenced in a fed or fasted state. Applied Physiology, Nutrition, and Metabolism, 38(2), 134-139. PubMed ID: 23438223 doi:10.1139/apnm-2012-0300

Leckey, J.J., Hoffman, N.J., Parr, E.B., Devlin, B.L., Trewin, A.J., Stepto, N.K., . . Hawley, J.A. (2018). High dietary fat intake increases fat oxidation and reduces skeletal muscle mitochondrial respiration in trained humans. FASEB Journal, 32(6), 2979-2991. PubMed ID: 29401600 doi:10.1096/fj.201700993R

Marquet, L.A., Brisswalter, J., Louis, J., Tiollier, E., Burke, L.M., Hawley, J.A., \& Hausswirth, C. (2016a). Enhanced endurance performance by periodization of carbohydrate intake: "Sleep Low" strategy. Medicine \& Science in Sports \& Exercise, 48(4), 663-672. doi:10.1249/MSS. 0000000000000823

Marquet, L.A., Hausswirth, C., Molle, O., Hawley, J.A., Burke, L.M., Tiollier, E., \& Brisswalter, J. (2016b). Periodization of carbohydrate intake: Short-term effect on performance. Nutrients, 8(12), pii: E755. PubMed ID: 27897989 doi:10.3390/nu8120755

McInerney, P., Lessard, S.J., Burke, L.M., Coffey, V.G., Lo Giudice, S.L., Southgate, R.J., \& Hawley, J.A. (2005). Failure to repeatedly supercompensate muscle glycogen stores in highly trained men. Medicine \& Science in Sports \& Exercise, 37(3), 404-411. PubMed ID: 15741838 doi:10.1249/01.MSS.0000155699.51360.2F

Miall, A., Khoo, A., Rauch, C., Snipe, R.M.J., Camoes-Costa, V.L., Gibson, P.R., \& Costa, R.J.S. (2018). Two weeks of repetitive gut-challenge reduce exercise-associated gastrointestinal symptoms and malabsorption. Scandinavian Journal of Medicine and Science in Sports, 28(2), 630-640 doi:10.1111/sms.12912

Mirtschin, J.G., Forbes, S.F., Cato, L.E., Heikura, I.A., Strobel, N., Hall, R., .. Burke, L.M. (2018). Organization of dietary control for nutrition-training intervention involving periodized carbohydrate availability and ketogenic low-carbohydrate high-fat diet. International Journal of Sport Nutrition and Exercise Metabolism, 28. doi: 10.1123/ijsnem.2017-0249

Morton, J., \& Fell, J.M. (2016). Nutritional strategies for the Tour de France. Aspetar Sports Medicine of Journal. Retrieved from http:// www.aspetar.com/journal/viewarticle. $a s p x$ ?id=341\#.W3wBps4zZI0

Noakes, T., Volek, J.S., \& Phinney, S.D. (2014). Low-carbohydrate diets for athletes: What evidence? British Journal of Sports Medicine, 48(14), 1077-1078. doi:10.1136/bjsports-2014-093824

Palfreeman, R. (2016). Chris Froome. Aspetar Sports Medicine of Journal. Retrieved from http://www.aspetar.com/journal/viewarticle.aspx?id= 342\#.W1h3odUzZI0

Philp, A., Hargreaves, M., \& Baar, K. (2012). More than a store: Regulatory roles for glycogen in skeletal muscle adaptation to exercise. American Journal of Physiology Endocrinology and Metabolism, 302(11), E1343-E1351. doi:10.1152/ajpendo.00004.2012

Phinney, S.D., Bistrian, B.R., Evans, W.J., Gervino, E., \& Blackburn, G.L. (1983). The human metabolic response to chronic ketosis without caloric restriction: Preservation of submaximal exercise capability with reduced carbohydrate oxidation. Metabolism: Clinical and Experimental, 32(8), 769-776. doi:10.1016/0026-0495(83)90106-3

Pilegaard, H., Osada, T., Andersen, L.T., Helge, J.W., Saltin, B., \& Neufer, P.D. (2005). Substrate availability and transcriptional regulation of metabolic genes in human skeletal muscle during recovery from exercise. Metabolism: Clinical and Experimental 54(8), 1048-1055. doi:10.1016/j.metabol.2005.03.008 
Pinckaers, P.J., Churchward-Venne, T.A., Bailey, D., \& van Loon, L.J. (2017). Ketone bodies and exercise performance: The next magic bullet or merely hype? Sports Medicine, 47(3), 383-391. PubMed ID: 27430501 doi:10.1007/s40279-016-0577-y

Sale, C., Varley, I., Jones, T.W., James, R.M., Tang, J.C.Y., Fraser, W.D., \& Greeves, J.P. (2015). Effect of carbohydrate feeding on the bone metabolic response to running. Journal of Applied Physiology, 119(7), 824-830. PubMed ID: 26251510 doi:10.1152/japplphysiol. 00241.2015

Sherman, W.M., Costill, D.L., Fink, W.J., \& Miller, J.M. (1981). Effect of exercise-diet manipulation on muscle glycogen and its subsequent utilisation during performance. International Journal of Sports Medicine, 2, 114-118. doi:10.1055/s-2008-1034594

Spriet, L.L. (2014). New insights into the interaction of carbohydrate and fat metabolism during exercise. Sports Medicine, 44(Suppl. 1), 87-96. doi:10.1007/s40279-014-0154-1

Stellingwerff, T. (2012). Case study: Nutrition and training periodization in three elite marathon runners. International Journal of Sport Nutrition and Exercise Metabolism, 22(5), 392-400. doi:10.1123/ ijsnem.22.5.392

Stellingwerff, T., Spriet, L.L., Watt, M.J., Kimber, N.E., Hargreaves, M., Hawley, J.A., \& Burke, L.M. (2006). Decreased PDH activation and glycogenolysis during exercise following fat adaptation with carbohydrate restoration. American Journal of Physiology Endocrinology and Metabolism, 290(2), E380-E388. PubMed ID: 16188909 doi: 10.1152/ajpendo.00268.2005

Tarnopolsky, M.A., Zawada, C., Richmond, L.B., Carter, S., Shearer, J., Graham, T., \& Phillips, S.M. (2001). Gender differences in carbohydrate loading are related to energy intake. Journal of Applied Physiology, 91, 225-230. PubMed ID: 11408434 doi:10.1152/jappl.2001.91.1.225

Thomas, D.T., Erdman, K.A., \& Burke, L.M. (2016). American College of Sports Medicine joint position statement. nutrition and athletic performance. Medicine \& Science in Sports \& Exercise, 48(3), 543-568. PubMed ID: 26891166 doi:10.1249/MSS.0000000000000852
Townsend, R., Elliott-Sale, K.J., Currell, K., Tang, J., Fraser, W.D., \& Sale, C. (2017). The effect of postexercise carbohydrate and protein ingestion on bone metabolism. Medicine \& Science in Sports \& Exercise, 49(6), 1209-1218. PubMed ID: 28121797 doi:10.1249/ MSS.0000000000001211

Vandoorne, T., De Smet, S., Ramaekers, M., Van Thienen, R., De Bock, K., Clarke, K., \& Hespel, P. (2017). Intake of a ketone ester drink during recovery from exercise promotes mTORC1 signaling but not glycogen resynthesis in human muscle. Frontiers in Physiology, 8, 310. PubMed ID: 28588499 doi:10.3389/fphys.2017.00310

Volek, J.S., Freidenreich, D.J., Saenz, C., Kunces, L.J., Creighton, B.C., Bartley, J.M., ... Phinney, S.D. (2016). Metabolic characteristics of keto-adapted ultra-endurance runners. Metabolism: Clinical and Experimental, 65(3), 100-110. doi:10.1016/j.metabol.2015. 10.028

Volek, J.S., Noakes, T., \& Phinney, S.D. (2015). Rethinking fat as a fuel for endurance exercise. European Journal of Sport Science, 15(1), 13-20. doi:10.1080/17461391.2014.959564

Volek, J.S., \& Phinney, S.D. (2012). The art and science of low carbohydrate performance. Beyond Obesity LLC.

Webster, C.C., Noakes, T.D., Chacko, S.K., Swart, J., Kohn, T.A., \& Smith, J.A. (2016). Gluconeogenesis during endurance exercise in cyclists habituated to a long-term low carbohydrate high-fat diet. Journal of Physiology, 594(15), 4389-4405. PubMed ID: 26918583 doi:10.1113/JP271934

Webster, C.C., Swart, J., Noakes, T.D., \& Smith, J.A. (2017). A carbohydrate ingestion intervention in an elite athlete who follows a LCHF diet. International Journal of Sports Physiology and Performance, 13(7), 957-960. doi:10.1123/ijspp.2017-0392

Yeo, W.K., Paton, C.D., Garnham, A.P., Burke, L.M., Carey, A.L., \& Hawley, J.A. (2008). Skeletal muscle adaptation and performance responses to once a day versus twice every second day endurance training regimens. Journal of Applied Physiology, 105(5), 1462 1470. PubMed ID: 18772325 doi:10.1152/japplphysiol.90882.2008 